\title{
Synthesis and luminescent properties of $\mathrm{SrTiO}_{3}: \mathrm{Pr}^{3+}$ phosphors prepared by sol-gel method
}

\author{
O.M. Marchylo ${ }^{1}$, L.V. Zavjalova ${ }^{1}$, Y. Nakanishi ${ }^{2}$, H. Kominami ${ }^{2}$, K. Hara ${ }^{2}$, A.E. Belyaev ${ }^{1}$, G.S. \\ Svechnikov ${ }^{1}$, L.I. Fenenko ${ }^{1}$, V.I. Poludin ${ }^{1}$ \\ ${ }^{1}$ V. Lashkaryov Institute of Semiconductor Physics, National Academy of Science of Ukraine, \\ 41, prospect Nauky, 03028 Kiev, Ukraine \\ ${ }^{2}$ Research Institute of Electronics, Shizuoka University, 3-5-1 Johoku, Naka-ku, Hamamatsu 432-8011, Japan
}

\begin{abstract}
New red $\mathrm{SrTiO}_{3}: \mathrm{Pr}^{3+}$ phosphor for the field emission displays application was prepared using the sol-gel method. The reaction between starting materials $\mathrm{SrCl}_{2}$, Ti-(Oi- $\left.\mathrm{C}_{3} \mathrm{H}_{7}\right)_{4}$ and $\mathrm{PrCl}_{3}$ resulted in a mix of compounds transformed to single-phase $\mathrm{SrTiO}_{3}: \mathrm{Pr}$ after its annealing in air. Optimal technological conditions for preparation of efficiently radiating $\mathrm{SrTiO}_{3}: \operatorname{Pr}^{3+}$ phosphors were found. Both photoluminescence and cathodoluminescence spectra showed the high intensity red peaks at the wavelength $\lambda_{\max }=617 \mathrm{~nm}$. The high luminance of $300 \mathrm{~cd} / \mathrm{m}^{2}$ was obtained at the anode voltage of $10 \mathrm{kV}$..
\end{abstract}

Keywords: phosphor, $\mathrm{SrTiO}_{3}: \mathrm{Pr}$, photoluminescence, cathodoluminescence, field emission displays, sol-gel method.

Manuscript received 25.06.09; accepted for publication 10.09.09; published online 30.10.09.

\section{Introduction}

Field emission displays (FEDs) operating due to electron beam excitation are very attractive and promising because of their advantages, namely: high luminance and contrast, high speed response, wide view angle, wide operating temperature range and a low power consumption $[1,2]$. In recent years, many efforts were devoted to develop the high performance phosphors for FEDs. Especially interesting in all the variety of investigated materials are red emitting phosphors with high luminance and color purity. A new red emitting $\mathrm{SrTiO}_{3}: \mathrm{Pr}^{3+}$ phosphor has been investigated and characterized [3-5]. $\mathrm{SrTiO}_{3}: \operatorname{Pr}^{3+}$ phosphors have been synthesized by mixing $\mathrm{SrCO}_{3}, \mathrm{TiO}_{2}$ and $\mathrm{PrCl}_{3}$ with the subsequent sintering and crushing of the prepared powder.The obtained phosphor shows high luminescent characteristics and can be considered as one of the promising materials for the high quality FEDs application.

In this study, to synthesize $\mathrm{SrTiO}_{3}: \mathrm{Pr}^{3+}$ phosphors we used the sol-gel method with starting materials $\mathrm{SrCl}_{3}$, Ti- $\left(\mathrm{O}-\mathrm{i}-\mathrm{C}_{3} \mathrm{H}_{7}\right)_{4}$ and $\mathrm{PrCl}_{3}$. Using this method, we assumed to get more complete reaction between the starting materials and more uniform distribution of dopant into the host lattice. In this paper, we analyze the structural and luminescent properties of the synthesized phosphor $\mathrm{SrTiO}_{3}: \mathrm{Pr}^{3+}$ depending on technological conditions.

\section{Synthesis}

Preparation of $\mathrm{SrTiO}_{3}: \mathrm{Pr}^{3+}$ phosphor is shown in Fig. 1 [6]. The synthesis was carried out in nitrogen atmosphere. The starting materials were strontium chloride $\mathrm{SrCl}_{2}$, praseodymium chloride $\mathrm{PrCl}_{3}$ and titanium tetra-i-propoxide Ti- $\left(\mathrm{O}-\mathrm{i}-\mathrm{C}_{3} \mathrm{H}_{7}\right)_{4}$ with a corresponding ratio of the starting materials $\mathrm{Sr}$ and $\mathrm{Ti}$ $\mathrm{Sr} / \mathrm{Ti}=1$ and the fixed concentration of $\mathrm{Pr}^{3+}$ of $1 \mathrm{~mol} . \%$. After dissolving the starting materials in alcohol and stirring the solution during 3 hours, the solvent was evaporated (under the further stirring) until gel was obtained. This gel was dried at the temperature $150{ }^{\circ} \mathrm{C}$ and sintered in a muffle furnace CNOL 6.7/1300. Sintering was carried out within the temperature range $1000-1300{ }^{\circ} \mathrm{C}$ in air during 2 to 9 hours. Finally, the obtained material was crushed into powder.

\section{Results and Discussion}

\subsection{XRD-analysis}

A structural analysis of the prepared phosphors was carried out using the X-ray diffractometer DRON-3M with $\mathrm{Cu} \mathrm{K} \alpha$ radiation $(\lambda=1.542 \AA)$. The samples annealed in the temperature range $1000-1250{ }^{\circ} \mathrm{C}$ during 3 hours were investigated and analyzed. As shown in Fig. 2, the crystals annealed at the lowest temperature $\left(1000{ }^{\circ} \mathrm{C}\right)$ consist of basic material $\mathrm{SrTiO}_{3}$ and additional 


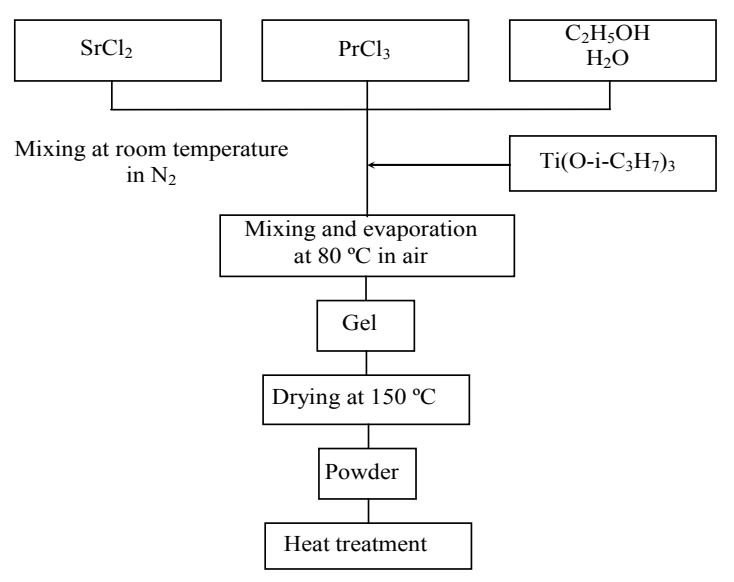

Fig. 1. Preparation of $\mathrm{SrTiO}_{3}: \mathrm{Pr}^{3+}$ phosphor.

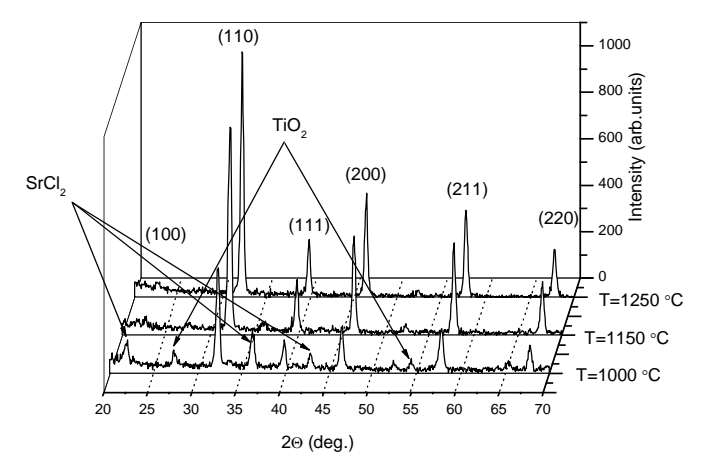

Fig. 2. The XRD spectra of samples annealed at various temperatures $\left(1000-1250{ }^{\circ} \mathrm{C}\right)$.

phases $\mathrm{TiO}_{2}$ and $\mathrm{SrCl}_{2}$. An increase of the sintering temperature results in a gradual decrease of $\mathrm{TiO}_{2}$ and $\mathrm{SrCl}_{2}$ peaks intensity to zero (at $\left.1250^{\circ} \mathrm{C}\right)$.

\subsection{Photoluminescence spectra}

The photoluminescence (PL) spectra were measured in the wavelength range $450-700 \mathrm{~nm}$ under nitrogen laser excitation (excitation wavelength $337 \mathrm{~nm}$, pulse duration $8 \mathrm{~ns}$ ) at the width of the measuring strobe $75 \mu \mathrm{s}$. Investigated $\mathrm{SrTiO}_{3}: \mathrm{Pr}$ samples were annealed in air within the temperature range of $1000-1300^{\circ} \mathrm{C}$ during 2 to 9 hours.

The photoluminescence spectra of the samples annealed at various temperatures (annealing time $t_{\mathrm{ann}}=$ const $=3 \mathrm{~h}$ ) are shown in Fig. 3 and have three peaks with a main maximum at the wavelength $\lambda_{\max }=617 \mathrm{~nm}$. The blue emission at $\lambda_{\max 1}=488 \mathrm{~nm}$ corresponds to the intra-4f transition from the excited state ${ }^{3} \mathrm{P}_{0}$ to the ground state ${ }^{3} \mathrm{H}_{4}$ of $\mathrm{Pr}^{3+}$, the green emission at $\lambda_{\max 2}=530 \mathrm{~nm}$ corresponds to the intra- $4 \mathrm{f}$ transition from the excited state ${ }^{3} \mathrm{P}_{0}$ to the ground state ${ }^{3} \mathrm{H}_{5}$, and the red emission at $\lambda_{\max 3}=617 \mathrm{~nm}$ corresponds to the intra4f transition from the excited state ${ }^{1} \mathrm{D}_{2}$ to the ground state ${ }^{3} \mathrm{H}_{4}[7,8]$.

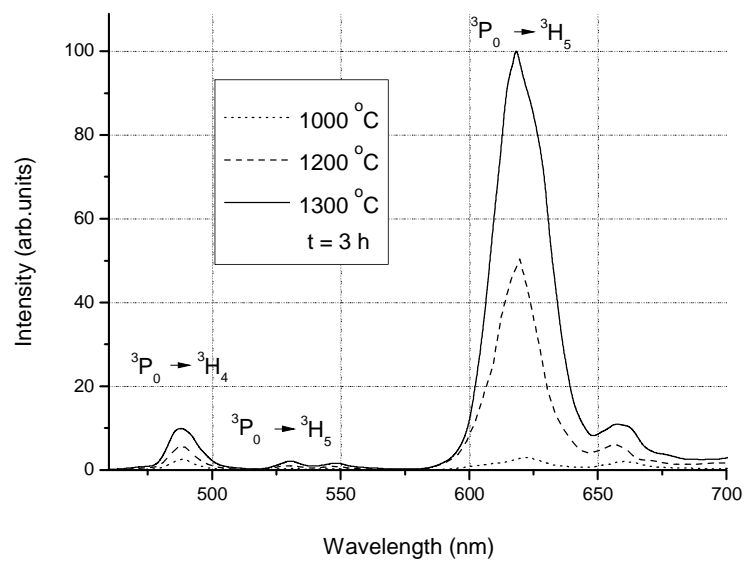

Fig. 3. The photoluminescence spectra of samples annealed at various temperatures $\left(1000-1300^{\circ} \mathrm{C}\right)$.

An increase in the annealing temperature from 1000 to $1300{ }^{\circ} \mathrm{C}$ results in redistribution of the intensities of PL peaks. In particular, 35-times increase of the red peak intensity was observed, while an increase of the blue peak intensity was insignificant.

The photoluminescence of $\mathrm{SrTiO}_{3}: \mathrm{Pr}^{+}$phosphor originates in absorption of excitation energy of the laser beam by host material $\mathrm{SrTiO}_{3}$, transferring to the $\mathrm{Pr}^{3+}$ luminescence centers and subsequent radiative recombination.

\subsection{Cathodoluminescence spectra}

The cathodoluminescence (CL) spectra of $\mathrm{SrTiO}_{3}: \mathrm{Pr}$ samples are shown in Fig. 4. It was observed that increase in the annealing temperature $\left(t_{\mathrm{ann}}=\right.$ const $\left.=3 \mathrm{~h}\right)$ results in a monotonic growth of the cathodeluminescence red band intensity from $2.8 \mathrm{arb}$. units at $T_{\text {ann }}=1100{ }^{\circ} \mathrm{C}$ to $100 \mathrm{arb}$. units at $T_{\mathrm{ann}}=1300^{\circ} \mathrm{C}$.

On the other hand, at the annealing temperature $T_{\text {ann }}=$ const $=1300{ }^{\circ} \mathrm{C}$ monotonic increase of the cathodoluminescence red band intensity with increase of the annealing time from 30 arb. units at $t_{\mathrm{ann}}=2 \mathrm{~h}$ to 100 arb. units at $t_{\mathrm{ann}}=9 \mathrm{~h}$ was observed (Fig. 5).

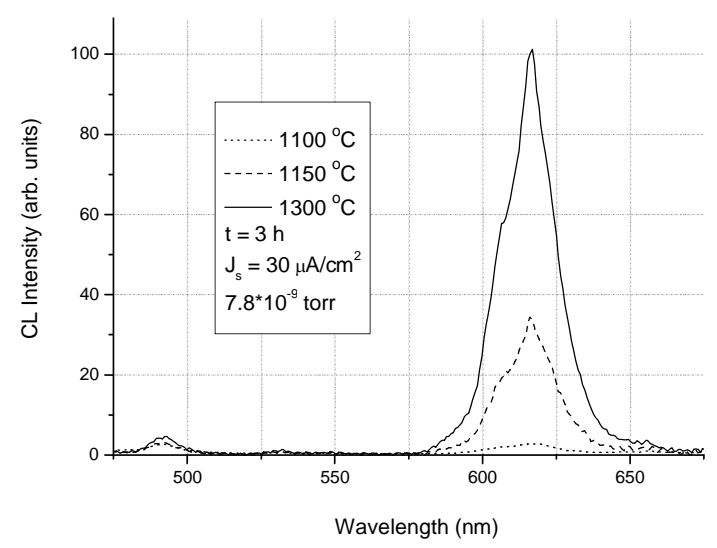

Fig. 4. The cathodoluminescence spectra of samples annealed at various temperatures $\left(1000-1300{ }^{\circ} \mathrm{C}\right)$. 


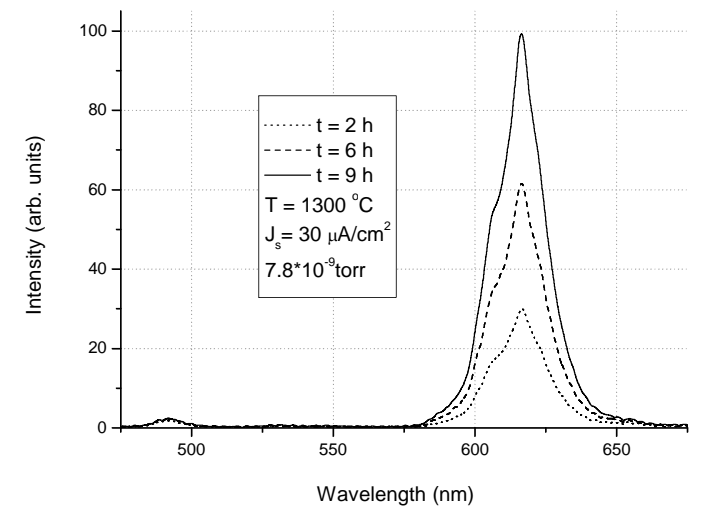

Fig. 5. The cathodoluminescence spectra of samples annealed for various times ( $2-9$ hours $)$.

It was shown that the samples annealed at the lowest temperature $\left(T_{\text {ann }}\right)$ and annealing time $\left(t_{\text {ann }}\right)$ had a low luminance $\left(5-25 \mathrm{~cd} / \mathrm{m}^{2}\right)$. Increase in the annealing temperature and annealing time up to maximal values results in growth of the luminance up to $300 \mathrm{~cd} / \mathrm{m}^{2}$ (Figs 6, 7).

The photoluminescence and cathodoluminescence mechanisms supposed to be the same ones. The cathodoluminescence of $\mathrm{SrTiO}_{3}: \mathrm{Pr}^{3+}$ phosphor originates in excitation of host material $\mathrm{SrTiO}_{3}$ by transfer of the electron beam energy to the $\operatorname{Pr}^{3+}$-luminescence centers and subsequent radiative recombination.

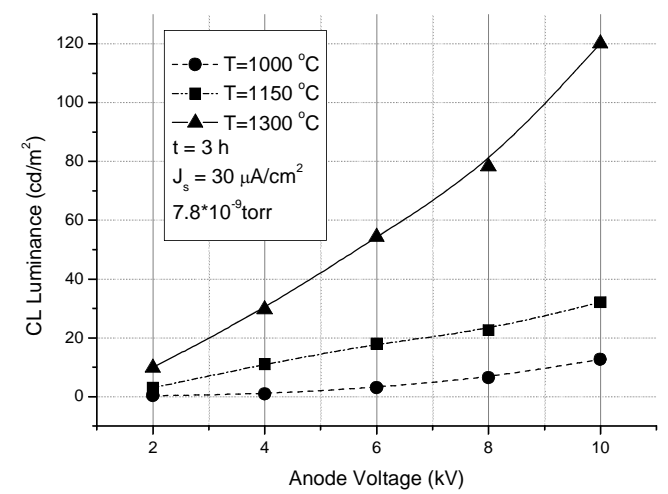

Fig. 6. Dependences of the $\mathrm{SrTiO}_{3}: \mathrm{Pr}^{3+}$ cathodoluminescence intensity on the anode voltage at various annealing temperatures $\left(1000-1300{ }^{\circ} \mathrm{C}\right)$.

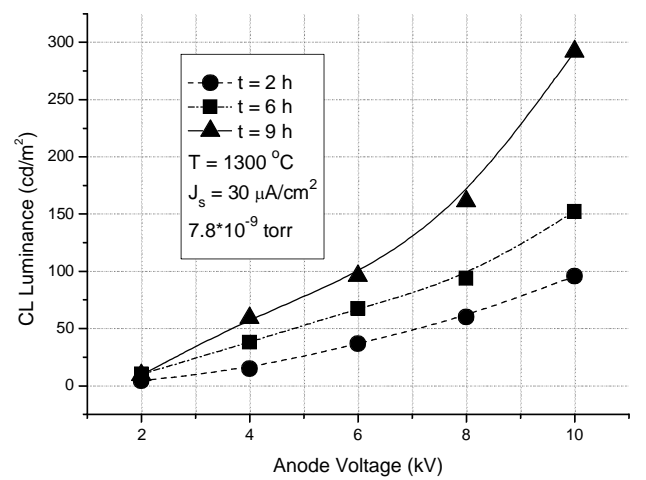

Fig. 7. Dependences of the $\mathrm{SrTiO}_{3}: \mathrm{Pr}^{3+}$ cathodoluminescence intensity on the anode voltage at various annealing times $(2-$ 9 hours).

\section{Conclusions}

It was shown that the mix of compounds $\mathrm{SrCl}_{2}$, Ti-(O-i$\left.\mathrm{C}_{3} \mathrm{H}_{7}\right)_{4}$ and $\mathrm{PrCl}_{3}$ can be transformed to single-phase $\mathrm{SrTiO}_{3}: \mathrm{Pr}$ phosphor. With increase in a sintering temperature from 1000 to $1250{ }^{\circ} \mathrm{C}$ the intensities of $\mathrm{SrTiO}_{3}$ peaks were increased. At the same time, the intensities of $\mathrm{TiO}_{2}$ and $\mathrm{SrCl}_{2}$ peaks were decreased to zero at $1250{ }^{\circ} \mathrm{C}$. With increase in the annealing temperature from 1000 to $1250^{\circ} \mathrm{C}$ the red peak $\left(\lambda_{\max }=617 \mathrm{~nm}\right)$ intensity was 35 times increased. With increase in the annealing temperature and annealing time to maximal values the CL brightness increases up to $300 \mathrm{~cd} / \mathrm{m}^{2}$.

The experimental results show that ${ }^{1} \mathrm{D}_{2} \rightarrow{ }^{3} \mathrm{H}_{4}$ transitions are more significant than ${ }^{3} \mathrm{P}_{0} \rightarrow{ }^{3} \mathrm{H}_{4}$ transitions when the temperature and time of annealing are high and long, respectively. It can be explained by the change of the $\mathrm{Pr}^{3+}-\mathrm{O}^{2-}$-distance, when the shortest distance $\mathrm{Pr}^{3+}-\mathrm{O}^{2-}$ is less than the critical value $(0.24 \mathrm{~nm})$ [3]

We have shown that phosphor $\mathrm{SrTiO}_{3}: \operatorname{Pr}$ prepared by the sol-gel method can be a promising material for further researches and applications as a red-emitting phosphor for the field emission displays.

\section{Acknowledgements}

We are grateful to the researchers from V.E. Lashkaryov Institute of Semiconductor Physics of NAS of Ukraine Dr. E. Manoilov for PL measurements and Dr. A. Korchevoj for XRD ones.

\section{References}

1. R.O. Peterson, Extended Abstracts of $1^{\text {st }}$ Int. Conf. on Sci. \& Technol. of Display Phosphors. San Diego, CA, 1995, p. 11.

2. S. Itoh et al., Extended Abstracts of $3^{\text {rd }}$ Int. Conf. on Sci. \& Technol. of Display Phosphors. Huntington Beach, CA, 1995, p. 275.

3. S. Itoh, H. Toki, K. Tamura and F. Kataoka, A new red-emitting phosphor, $\mathrm{SrTiO}_{3}: \mathrm{Pr}^{3+}$, for lowvoltage electron excitation // Jpn. J. Appl. Phys. 38(11), p. 6387-6391 (1999).

4. S. Okamoto, S. Tanaka and H. Yamamoto, Reduction process of Ruddlesden-Popper-type planar faults in $\mathrm{SrTiO}_{3}: \mathrm{Pr}^{3+}$ by $\mathrm{Al}$ addition // Electrochem. and Solid-State Lett. 3(5), p. 242-244 (2000).

5. J.Y. Kim, Y.C. You and D.Y. Jeon, Investigation of the characteristic changes on SrTiO3:Pr,Al,Ga phosphors during low voltage electron irradiation // J. Vac. Sci. Technol. B 21(1), p. 536-539 (2003).

6. H. Kominami, M. Tanaka, Y. Nakanishi, Y. Hatanaka, Synthesis and luminescence properties of Mg-Ti-O:Eu red-emitting phosphors // Phys. status solidi (c) 3(8), p. 2758-2761 (2006).

7. S. Okamoto, H. Kobayashi, H. Yamamoto, Effects of $\mathrm{Al}$ addition on photoluminescence properties in rare-earth ion-doped $\mathrm{SrTiO}_{3} / /$ J. Electrochem. Soc. 147(6), p. 2389-2393 (2000).

8. M. Okumura, M. Tamatani, A.K. Albessard and N. Matsuda, Luminescence properties of rare earth ion-doped monoclinic yttrium sesquioxide // Jpn. J. Appl. Phys. 36, p. 6411 (1997). 